\title{
Structure-function relationships of Nile blue (EtNBS) derivatives as antimicrobial photosensitizers
}

\author{
Daniela Vecchio ${ }^{11,2}$, Brijesh Bhayana $\# 1$, Liyi Huang ${ }^{1,2,3}$, Elisa Carrasco ${ }^{1,4,5}$, Conor L \\ Evans $^{1,2}$, and Michael R Hamblin ${ }^{1,2,6, \S}$ \\ ${ }^{1}$ Wellman Center for Photomedicine, Massachusetts General Hospital, Boston, MA 02114, USA \\ 2 Department of Dermatology, Harvard Medical School, Boston, MA 02115, USA \\ ${ }^{3}$ Department of Infectious Diseases, First Affiliated College \& Hospital, Guangxi Medical \\ University, Nanning, China 530021 \\ 4 Departamento de Biología, Facultad de Ciencias, Universidad Autónoma de Madrid, Madrid, \\ Spain \\ 5 Instituto de Investigaciones Biomédicas "Alberto Sols", CSIC-Departamento de Bioquímica, \\ Facultad de Medicina, Universidad Autónoma de Madrid, Madrid, Spain \\ ${ }^{6}$ Harvard-MIT Division of Health Sciences and Technology, Cambridge, MA 02139, USA \\ \# These authors contributed equally to this work.
}

\section{Abstract}

The benzophenothiazinium dye EtNBS has previously been tested as a photosensitizer to mediate photodynamic therapy (PDT). It has been employed to kill cancer cells and microbial cells in vitro and to treat tumors and infections in vivo. We synthesized a panel of derivatives substituted at the 1-position of the benzene ring with electron donating or electron withdrawing groups (amino, acetamido and nitro) and tested their production of reactive oxygen species (ROS) and lightmediated killing of two species of Gram-positive and two species of Gram-negative bacteria. All three compounds showed lower fluorescence, lower yield of ROS and less microbial killing than parent EtNBS, while the order of activity (nitro>amino>acetamido) showed that an electron withdrawing substituent was better than electron donating. To test the hypothesis that 1substitution distorts the planar structure of the conjugated rings we compared two compounds substituted with N-ethylpropylsulfonamido either at the 1-position or at the 4-position. The 4isomer was significantly more photoactive than the 1-isomer. We also prepared an EtNBS derivative with a guanidinium group attached to the 5-amino group. This compound had high activity against Gram-negative bacteria due to the extra positive charge. Cellular uptake of the compounds by the four bacterial species was also measured and broadly correlated with activity. These results provided three separate pieces of structure-activity relationship data for antimicrobial photosensitizers based on the EtNBS backbone

(C) 2014 Elsevier Masson SAS. All rights reserved.

$\S$ correspondence to: Michael R Hamblin, PhD. BAR414, 40 Blossom Street, Boston, MA 02114, USA. Tel: 1-617-726-6182; Hamblin@ helix.mgh.harvard.edu.

Publisher's Disclaimer: This is a PDF file of an unedited manuscript that has been accepted for publication. As a service to our customers we are providing this early version of the manuscript. The manuscript will undergo copyediting, typesetting, and review of the resulting proof before it is published in its final citable form. Please note that during the production process errors may be discovered which could affect the content, and all legal disclaimers that apply to the journal pertain. 


\section{Keywords}

Structure activity relationships; benzophenothiazinium dye; Nile blue derivatives; antimicrobial photodynamic inactivation; Gram-positive bacteria; Gram-negative bacteria; electron withdrawing/donating substituents

\section{INTRODUCTION}

One of the major problems in the management of infectious disease today is the inexorable worldwide increase in antibiotic resistance occurring in different bacterial species [1]. This problem has led to increasing interest in the discovery of new antimicrobial treatments that will be equally effective against multi-drug resistant strains. Since its discovery over a century ago, photodynamic therapy (PDT) is now emerging as a new clinical approach to infections [2] as well as cancer [3]. PDT is already approved as an effective method for treatment of solid tumors in humans [3] as well as age-related macular degeneration and other indications in ophthalmology [4]. The application of PDT as an antimicrobial treatment involves the topic (or less likely systemic) application of a non-toxic dye called a photosensitizer (PS), followed by delivery of light of an appropriate wavelength in the presence of ambient molecular oxygen. The absorption of a photon is able to excite the PS to its excited singlet state that can convert to a long-lived triplet state that can then react with oxygen, producing reactive oxygen species (ROS), or with other molecules producing radicals through two complementary pathways, Type I (electron transfer) and Type II (energy transfer) processes. ROS (singlet oxygen and hydroxyl radicals) can react with many cellular components. These reactive radical species are able to oxidize biomolecules such as amino acids, nucleotides and unsaturated lipids inducing cell death [5]. The spectrum of microbial targets of PDT is very broad including viruses, all classes of bacteria, fungi and parasites. It was observed that the activity of PDT is different towards Grampositive and Gram-negative bacteria and this is mainly due to the structural differences in the cellular architecture primarily of the bacterial cell wall [6]. Gram-positive bacteria and fungi are more susceptible to PDT because their cytoplasmic membrane is surrounded by a relatively porous layer of peptidoglycan and lipoteichoic acid, or beta-glucan and chitin, respectively; these structures allow easier penetration of PS [7]. Many studies have been carried out to improve antimicrobial PDT against Gram-negative species [8]. Clinically antimicrobial PDT has been widely applied in dentistry where it is used to kill periodontopathogenic bacteria in the dental pocket to treat periodontitis, and to sterilize root canals in endodontic therapy $[9,10]$.

An important factor to increase and improve the efficacy of PDT is to optimize the structure of the PS. The Nile blue derivative, 5-(ethylamino)-9-diethylamino-

benzo $[a]$ phenothiazinium chloride (EtNBS) in combination with red light has been reported to be able to mediate killing of cancer cells [11] and 3D cancer models [12, 13] in vitro, and to treat tumors in vivo [14-16]. Furthermore its positive charge suggested it could mediate photodestruction of a wide range of microorganisms. Foley et al. [17] evaluated the antimicrobial PDT efficacies of EtNBS and two chalcogen derivatives (EtNBA, oxygen, and EtNBSe, selenium) against the Gram-positive bacterium Enterococcus faecalis, the Gramnegative bacterium Escherichia coli, and the yeast Candida albicans. In another study [18] the PDT activity of EtNBS and EtNBSe against Mycobacterium bovis BCG was evaluated in both in vitro and in vivo models. Later, Verma et al. [19] investigated the antimicrobial photodynamic activity of two EtNBS derivatives containing functional group modifications to enhance specificity and these compounds were tested on two representative Grampositive and Gram-negative bacterial strains. EtNBS and EtNBSe have also been used to mediate PDT destruction of Leishmaniasis parasites in vitro [20]. 
EtNBS derivative compounds to date have largely been created through modifications to the amine side groups or through replacement of the central ring chalcogen. These modifications are functionally orthogonal, with the heavier chalcogen (Se) derivative leading to increased intersystem crossing and subsequent singlet oxygen production [17]. Side chain modifications, on the other hand, enable the tuning of properties such as molecular hydrophobicity and charge. Side chain derivatives were found to alter photosensitizer uptake, localization, and ultimately PDT efficacy both in the treatment of microorganisms and cancer [21].

Nile blue derivatives such as EtNBS have unique properties that make them good photosensitizers for anti-microbial therapy. Though EtNBS is a lipophilic compound, it also has a single charge delocalized throughout its ring system making the molecule readily water soluble. Containing only a single sulfur heteroatom in the ring, EtNBS actually has a relatively low singlet oxygen quantum yield of 3\% [19]. Nevertheless, EtNBS has been observed to be a potent photosensitizer. Recent studies investigating EtNBS and structural derivatives in vitro have found that the molecule can act via both Type I and Type II photochemical pathways. This consideration allows EtNBS to operate over a wide range of oxygen tensions, even in severely hypoxic environments [13,21]. This property could be of significant benefit, especially in the treatment of complex infections and biofilms where oxygen is not always present in high concentrations.

The high PDT activity of EtNBS and its derivatives, and the broad-spectrum of microbial targets observed in the previous reports taken together support more studies on new derivatives to better understand the structural features needed for improved efficacy of PDT. For this reason, in the present study we aimed to evaluate the effect of EtNBS and a panel of novel derivatives on two Gram-positive bacterial strains Staphylococcus aureus and E. faecalis and two Gram-negative strains, E. coli and Acinetobacter baumannii. Initially we tested three derivatives with electron-withdrawing (nitro, EtNBS-N) or electron-donating (amino, EtNBS-A and acetamido, EtNBS-Ac) groups prepared by substitution at the 1position of the benzene ring. We then tested the hypothesis that 1-substitution distorts the planar structure of the conjugated rings by comparing two compounds substituted with $\mathrm{N}$ ethylpropylsulfonamido either at the 1-position (EtNBS-So), or at the 4-position (EtNBS$\mathrm{Sp}$ ). Finally as small cationic molecules such as EtNBS have been found potent against microorganisms, the arginine side-chain (EtNBS-G) derivative was included in this study to examine the role of increased charge on photosensitizer uptake and activity. All the structures are shown in Table 1.

\section{Materials and methods}

\section{Synthesis of compounds}

5-(ethylamino)-9-diethylaminobenzo[a]phenothiazinium chloride (EtNBS) and Bunte Salt (sodium 2-amino-5-diethylaminophenylthiosulfuric acid) were prepared according to previously published procedures [22].

General method for synthesis of the EtNBS derivatives-A refluxing mixture of derivatized naphthylamine $(1.0 \mathrm{mmol})$ and Bunte salt $(138 \mathrm{mg}, 0.5 \mathrm{mmol})$ in $25 \mathrm{~mL}$ of methanol was charged with silver carbonate $(303 \mathrm{mg}, 1.1 \mathrm{mmol})$, and allowed to stir for about $30 \mathrm{~min}$. The deep blue reaction mixture was then filtered through a pad of celite and concentrated to near-dryness with the aid of a rotary evaporator. The resulting solid was portioned between $25 \mathrm{~mL}$ dichloromethane and $25 \mathrm{~mL}$ saturated sodium carbonate solution. The organic layer was separated, acidified with $\sim 0.25 \mathrm{~mL}$ conc. $\mathrm{HCl}$ and allowed to dry overnight in a fume hood. The crude product was purified by silica-gel chromatography using 5 - 10\% methanol in dichloromethane as the mobile phase. 
Derivatives EtNBS-A, EtNBS-Ac and EtNBS-G were further purified in small batches by reversed-phase high-performance liquid chromatography.

N-(9-(diethylamino)-1-nitro-5H-benzo[a]phenothiazin-5-ylidene)ethanaminium (EtNBS-N): This compound was synthesized starting with N-ethyl-5-nitronaphthalen-1amine. ${ }^{1} \mathrm{H}$ NMR (DMSO-d $\left.\mathrm{d}_{6}\right) \delta 9.93(\mathrm{~m}, 1 \mathrm{H}), 8.82(\mathrm{~d}, J=8.7 \mathrm{~Hz}, 1 \mathrm{H}), 8.30(\mathrm{~d}, J=7.8 \mathrm{~Hz}$, $1 \mathrm{H}), 8.07(\mathrm{t}, J=7.8 \mathrm{~Hz}, 1 \mathrm{H}), 7.7-7.5(\mathrm{~m}, 4 \mathrm{H}), 3.77(\mathrm{~m}, 6 \mathrm{H}), 1.42(\mathrm{t}, J=7.2 \mathrm{~Hz}, 3 \mathrm{H}), 1.29(\mathrm{t}$, $J=7.2 \mathrm{~Hz}, 6 \mathrm{H}$ ). MALDI-MS calculated for $\mathrm{C}_{22} \mathrm{H}_{23} \mathrm{~N}_{4} \mathrm{O}_{2} \mathrm{~S}+$ : 407.1; found 407.0. HPLC retention time $=22.3 \mathrm{~min}$, conditions: $\mathrm{C}-18$ reversed-phase column $(4.6 \mathrm{~mm} \times 250 \mathrm{~mm})$, eluting with $\mathrm{CH}_{3} \mathrm{CN}$ in water ( $20 \%$ to $100 \%$ in $25 \mathrm{~min}$ ) with a flow rate of $1.0 \mathrm{~mL} / \mathrm{min}$.

$\underline{\mathrm{N}-(1-a m i n o-9-(d i e t h y l a m i n o)-5 H-b e n z o[a] p h e n o t h i a z i n-5-y l i d e n e) e t h a n a m i n i u m ~}$ (EtNBS-A): This compound was synthesized starting with tert-butyl (5(ethylamino)naphthalen-1-yl)carbamate. ${ }^{1} \mathrm{H}$ NMR $\left(\right.$ DMSO-d $\left._{6}\right) \delta 9.92(\mathrm{br}, 1 \mathrm{H}), 8.5(\mathrm{br}, 2 \mathrm{H})$, 8.13 (br, m, 1H), $7.75(\mathrm{~m}, 1 \mathrm{H}), 7.7-7.5(\mathrm{~m}, 2 \mathrm{H}), 7.4-7.2(\mathrm{~m}, 3 \mathrm{H}), 3.83(\mathrm{q}, J=7.2 \mathrm{~Hz}, 2 \mathrm{H})$, $3.67(\mathrm{q}, J=6.9 \mathrm{~Hz}, 4 \mathrm{H}), 1.39$ (t, $J=7.2 \mathrm{~Hz}, 3 \mathrm{H}), 1.26(\mathrm{t}, J=6.9 \mathrm{~Hz}, 6 \mathrm{H})$. MALDI-MS calculated for $\mathrm{C}_{22} \mathrm{H}_{25} \mathrm{~N}_{4} \mathrm{~S}+: 377.17$; found 337. HPLC retention time $=23.7 \mathrm{~min}$, conditions: C-18 reversed-phase column $(4.6 \mathrm{~mm} \times 250 \mathrm{~mm})$, eluting with $\mathrm{CH}_{3} \mathrm{CN}$ in water ( $20 \%$ to $100 \%$ in $25 \mathrm{~min}$ ) with a flow rate of $1.0 \mathrm{~mL} / \mathrm{min}$.

$\underline{\text { N-(1-acetamido-9-(diethylamino)-5H-benzo[a]phenothiazin-5-ylidene)-ethanaminium }}$ (EtNBS-Ac): This compound was synthesized starting with N-(5-(ethylamino)naphthalen-1yl)acetamide. ${ }^{1} \mathrm{H}$ NMR (DMSO-d 6 ) $\delta 13.88(\mathrm{~s}, 1 \mathrm{H}), 10.05(\mathrm{t}, \mathrm{br}, J=6 \mathrm{~Hz}, 1 \mathrm{H}), 9.13(\mathrm{~d}, J=$ $7.8 \mathrm{~Hz}, 1 \mathrm{H}), 8.27(\mathrm{~d}, J=9 \mathrm{~Hz}, 1 \mathrm{H}), 7.99(\mathrm{~d}, J=9 \mathrm{~Hz}, 1 \mathrm{H}), 7.91(\mathrm{t}, J=8.1 \mathrm{~Hz}, 1 \mathrm{H}), 7.71(\mathrm{~s}$, $1 \mathrm{H}), 7.50(\mathrm{~m}, 2 \mathrm{H}), 3.83(\mathrm{~m}, J=7.2 \mathrm{~Hz}, 2 \mathrm{H}), 3.73(\mathrm{~m}, J=6.9 \mathrm{~Hz}, 4 \mathrm{H}), 2.44(\mathrm{~s}, 3 \mathrm{H}), 1.42(\mathrm{t}$, $J=7.2 \mathrm{~Hz}, 3 \mathrm{H}$ ), $1.29(\mathrm{t}, J=6.9 \mathrm{~Hz}, 6 \mathrm{H})$. MALDI-MS calculated for $\mathrm{C}_{24} \mathrm{H}_{27} \mathrm{~N}_{4} \mathrm{OS}+: 419.1$; found 419.0. HPLC retention time $=23.3 \mathrm{~min}$, conditions: $\mathrm{C}-18$ reversed-phase column (4.6 $\mathrm{mm} \times 250 \mathrm{~mm}$ ), eluting with $\mathrm{CH}_{3} \mathrm{CN}$ in water (20\% to $100 \%$ in $25 \mathrm{~min}$ ) with flow rate of $1.0 \mathrm{~mL} / \mathrm{min}$.

N-(9-(diethylamino)-1-(N-ethylpropylsulfonamido)-5H-benzo[a]phenothiazin-5ylidene)ethanaminium (EtNBS-So): This compound was synthesized starting with $\mathrm{N}$ ethyl-N-(5-(ethylamino)naphthalen-1-yl)propane-1-sulfonamide. ${ }^{1} \mathrm{H}$ NMR $\left(\right.$ DMSO-d $\left._{6}\right) \delta$ $9.73(\mathrm{~m}, 1 \mathrm{H}), 8.55(\mathrm{~d}, 1 \mathrm{H}, J=7.8 \mathrm{~Hz}), 8.21(\mathrm{~d}, 1 \mathrm{H}, J=9 \mathrm{~Hz}), 7.91(\mathrm{~m}, 2 \mathrm{H}), 7.56(\mathrm{~s}, 1 \mathrm{H})$, $7.48(\mathrm{~m}, 2 \mathrm{H}), 4.07(\mathrm{~m}, 1 \mathrm{H}), 3.75-3.64(\mathrm{~m}, 6 \mathrm{H}), 3.56-3.48(\mathrm{~m}, 1 \mathrm{H}), 3.22-3.15(\mathrm{~m}, 2 \mathrm{H})$, $1.71(\mathrm{~m}, 2 \mathrm{H}), 1.34(\mathrm{t}, 3 \mathrm{H}, J=7.2 \mathrm{~Hz}), 1.26(\mathrm{t}, J=6.9 \mathrm{~Hz}, 6 \mathrm{H}), 1.07(\mathrm{t}, J=7.2 \mathrm{~Hz}, 3 \mathrm{H}), 0.95$ $\left(\mathrm{t}, 3 \mathrm{H}, J=7.2 \mathrm{~Hz}\right.$ ). MALDI-MS calculated for $\mathrm{C}_{27} \mathrm{H}_{35} \mathrm{~N}_{4} \mathrm{~S}_{2} \mathrm{O}_{2}+: 511.21$; found 511. HPLC retention time $=24 \mathrm{~min}$, conditions: $\mathrm{C}-18$ reversed-phase column $(4.6 \mathrm{~mm} \times 250 \mathrm{~mm})$; eluting solvent: $\mathrm{CH}_{3} \mathrm{CN}$ in water (20\% to $100 \%$ in $25 \mathrm{~min}$ ) with flow rate of $1.0 \mathrm{~mL} / \mathrm{min}$

N-(9-(diethylamino)-4-(N-ethylpropylsulfonamido)-5H-benzo[a]phenothiazin-5ylidene)ethanaminium (EtNBS-Sp): This compound was synthesized starting with Nethyl-N-(8-(ethylamino)naphthalen-1-yl)propane-1-sulfonamide. ${ }^{1} \mathrm{H}$ NMR (DMSO-d 6 ) $\delta$ $10.11(\mathrm{~m}, 1 \mathrm{H}), 9.2(\mathrm{~d}, 1 \mathrm{H}, J=8.1 \mathrm{~Hz}), 8.1-8.05(\mathrm{~m}, 2 \mathrm{H}), 8.0(\mathrm{t}, 1 \mathrm{H}, J=8.1 \mathrm{~Hz}), 7.51(\mathrm{~m}$, $2 \mathrm{H}), 7.48(\mathrm{dd}, 1 \mathrm{H}, J=9.5 \mathrm{~Hz}$ and $J=3.3 \mathrm{~Hz}), 4.04(\mathrm{~m}, 2 \mathrm{H}), 3.9-3.6(\mathrm{~m}, 8 \mathrm{H}), 1.73(\mathrm{~m}$, $2 \mathrm{H}), 1.39(\mathrm{t}, 3 \mathrm{H}, J=7.2 \mathrm{~Hz}), 1.23(\mathrm{t}, J=6.9 \mathrm{~Hz}, 6 \mathrm{H}), 1.1(\mathrm{t}, J=7.2 \mathrm{~Hz}, 3 \mathrm{H}), 1.0(\mathrm{t}, 3 \mathrm{H}, J=$ 7.2 Hz). MALDI-MS calculated for $\mathrm{C}_{27} \mathrm{H}_{35} \mathrm{~N}_{4} \mathrm{~S}_{2} \mathrm{O}_{2}+: 511.21$; found 511. HPLC retention time $=25.5 \mathrm{~min}$, conditions: $\mathrm{C}-18$ reversed-phase column $(4.6 \mathrm{~mm} \times 250 \mathrm{~mm})$; eluting solvent: $\mathrm{CH}_{3} \mathrm{CN}$ in water ( $20 \%$ to $100 \%$ in $25 \mathrm{~min}$ ) with flow rate of $1.0 \mathrm{~mL} / \mathrm{min}$.

2-((amino(iminio)methyl)amino)-N-(9-(diethylamino)-5H-benzo[a]phenothiazin-5ylidene)ethanaminium (EtNBS-G): This compound was synthesized starting with N,N'-di- 
boc-N"-(2-(naphthalen-1-ylamino)ethyl)guanidine [23]. ${ }^{1} \mathrm{H}$ NMR (MeOD): $\delta 9.12$ (d, 1H, $J$ $=1.1 \mathrm{~Hz}), 8.33(\mathrm{~d}, 1 \mathrm{H}, J=8.0 \mathrm{~Hz}), 8.07(\mathrm{~d}, 1 \mathrm{H}, J=9.5 \mathrm{~Hz}), 7.92(\mathrm{t}, 1 \mathrm{H}, J=7.0 \mathrm{~Hz}), 7.83$ $(\mathrm{m}, 1 \mathrm{H}), 7.48(\mathrm{dd}, 1 \mathrm{H}, J=2.7 \mathrm{~Hz}$ and $J=9.5 \mathrm{~Hz}), 7.38(\mathrm{~s}, 1 \mathrm{H}), 7.32(\mathrm{~d}, 1 \mathrm{H}, J=2.7 \mathrm{~Hz})$, $3.91(\mathrm{t}, J=5.6 \mathrm{~Hz}, 2 \mathrm{H}), 3.73(\mathrm{q}, J=7.1 \mathrm{~Hz}, 4 \mathrm{H}), 3.7-3.65(\mathrm{~m}, 2 \mathrm{H}), 3.62(\mathrm{br}, 4 \mathrm{H}), 1.32(\mathrm{t}, J$ $=7.1 \mathrm{~Hz}, 6 \mathrm{H}$ ). MALDI-MS calculated for $\mathrm{C}_{23} \mathrm{H}_{27} \mathrm{~N}_{6} \mathrm{~S}+: 419.20$; found 419 . HPLC retention time $=20.0$ min, conditions: $\mathrm{C}-18$ reversed-phase column $(4.6 \mathrm{~mm} \times 250 \mathrm{~mm})$, eluting with $\mathrm{CH}_{3} \mathrm{CN}$ in water (20\% to $100 \%$ in $25 \mathrm{~min}$ ) with flow rate of $1.0 \mathrm{~mL} / \mathrm{min}$.

EtNBS and derivatives were dissolved in $N, N$-dimethylacetamide (DMA), final concentration $5 \mathrm{mM}$, and stored in the dark at $4{ }^{\circ} \mathrm{C}$.

\section{Spectra}

The absorbance and fluorescence emission spectra of all compounds (EtNBS and EtNBS derivatives at $10 \mu \mathrm{M}$ in both water and methanol) were measured. Fluorescence spectra were measured using the appropriate excitation maximum wavelength for each separate compound.

The calculated Log P values and TPSA (topological polar surface area [24]) values were obtained using ChemBioDraw Ultra (version 12.0.3.1216, Cambridgesoft, Cambridge, MA). The measured $\log P$ values were experimentally determined for all compounds (EtNBS and EtNBS derivatives). A mixture of $1.5 \mathrm{~mL}$ of octanol, $1.5 \mathrm{~mL}$ of PBS and $100 \mu \mathrm{M}$ of EtNBS or derivatives in a $10-\mathrm{mL}$ vial was stirred at room temperature overnight. The mixture was allowed to stand for $30 \mathrm{~min}$ to allow separation of the phases. The absorbance of $1 \mathrm{ml}$ aliquot of each phase, not diluted and diluted 1:2 and 1:10 was measured at specific peak of absorbance obtained from absorption spectra. The ratio of the two phases (octanol/PBS) was calculated; the $\log (10)$ of the measured ratios are hereafter denoted "meas $\log \mathrm{P}$ values".

\section{Light Source}

Bacterial suspensions were irradiated with $635 \mathrm{~nm} \pm 15 \mathrm{~nm}$ light delivered by a non-coherent light source fitted with a band-pass filter and a light guide (LumaCare, Newport Beach, CA). Although the absorption spectra of the compounds had differences between them it was considered that $635-\mathrm{nm}$ was the best single wavelength to excite them all. Fluence rates were routinely measured using a power meter (Coherent, Portland, OR).

\section{ROS generation assay}

Experiments on cell-free solutions were carried out in 96-well plates. All compounds were diluted in PBS to $5 \mu \mathrm{M}$ final concentration per well, and 3-(4-hydroxyphenyl)fluorescein (HPF) or singlet oxygen sensor green (SOSG) (Molecular Probes Invitrogen) was added to each well (final concentration $5 \mu \mathrm{M}$ ). Each experimental group contained 4 wells and all of them were illuminated simultaneously and 635-nm light was delivered in sequential doses of $1 \mathrm{~J} / \mathrm{cm}^{2}$ to $15 \mathrm{~J} / \mathrm{cm}^{2}$. The fluorescence signals were acquired by a microplate spectrophotometer (Spectra Max M5, Molecular Devices) in the "slow kinetic" mode. When HPF was employed, fluorescence emission at $515 \mathrm{~nm}$ was measured upon excitation at 490 $\mathrm{nm}$ using $2 \mathrm{~nm}$ monochromator bandpass for both excitation and emission. With SOSG, the corresponding values were 505 and $525 \mathrm{~nm}$, respectively.

\section{Bacterial culture}

Four bacterial strains were studied. Staphylococcus aureus 8325-4, and Enterococcus faecalis (ATCC29212) as Gram (+) bacteria; Acinetobacter baumanii (ATCC 51393), and Escherichia coli (ATCC53868) as Gram (-) bacteria. Bacteria were grown in brain-heart infusion (BHI) broth (Fischer Scientific), at $37^{\circ} \mathrm{C}$ overnight, in an orbital shaking incubator. 
Th e day after the incubation an aliquot was refreshed in new BHI medium and incubated at $37^{\circ} \mathrm{C}$ for $3 \mathrm{~h}$. The optical density at $600 \mathrm{~nm}$ was measured by a spectrophotometer (Thermo Scientific, Waltham, MA), $\mathrm{OD}_{600}=0.5$, corresponding to $10^{8}$ colony forming units (CFU)/ $\mathrm{ml}$. The suspensions were centrifuged (5 min, $3500 \mathrm{rpm}$ ) and the pellet was suspended in sterile PBS at concentration $10^{8} \mathrm{CFU} / \mathrm{ml}$ for phototoxicity experiments

\section{Photodynamic inactivation of bacteria in vitro}

Bacterial suspensions at concentration $10^{8} \mathrm{CFU} / \mathrm{mL}$ were incubated in PBS in the dark at room for 10 min with different concentrations of EtNBS and all derivatives in the range 0.1-100 $\mu \mathrm{M}$ (obtained by diluting $5 \mathrm{mM}$ DMA stock solutions of each compound). After the incubation with PS, $100 \mu \mathrm{L}$ aliquots of the cell suspensions were placed in 96 well plates. The wells were illuminated from the top of the plates by use of red light (635-nm) at a fluence $10 \mathrm{~J} / \mathrm{cm}^{2}$ delivered at an irradiance of $50 \mathrm{~mW} / \mathrm{cm}^{2}$. To determine the CFU, aliquots taken after illumination were serially diluted, streaked on nutrient agar according to the method of Jett et al [25], and incubated in the dark for $18 \mathrm{~h}$ at $37^{\circ} \mathrm{C}$. Experiments were carried out in triplicate for each condition. Controls using the same amount of organic solvent (2\% DMA), in the presence of each PS and without light, and with light alone, were performed for all experimental conditions, obtaining less than 1-log 10 reduction in bacterial viability in all cases.

\section{Uptake of compounds by bacterial cells}

Suspensions of microbial cells $\left(10^{8} / \mathrm{ml}\right)$ were incubated in the dark at room temperature for 10 minutes with concentrations in the range $0.05-10 \mu \mathrm{M}$ of all compounds. The cell suspensions were centrifuged, the supernatant was aspirated and bacteria were washed twice with PBS and centrifuged. The cell pellet was dissolved in $100 \mu \mathrm{l}$ of RIPA solution (PerkinElmer Inc., Waltham, MA) at room temperature for 30 minutes to give a homogeneous solution. The fluorescence of the cell lysates was measured using appropriate excitation and emission wavelength for each compound with a fluorescence plate reader (Molecular Devices, Sunnyvale CA). Following the fluorescence measurement, the total protein concentration was determined with a bicinchoninic acid protein assay kit (Sigma) using bovine serum albumin to prepare protein calibration curves. Individual fluorescence calibration curves were prepared for known concentrations of each of all compounds.

\section{Results}

Structures

The structures of the seven different EtNBS derivatives are shown in Table 1 together with the calculated and measured Log P and TPSA values. The correlation between measured and calculated $\log \mathrm{P}$ values is shown in supplementary Fig S4 with a $\mathrm{R}$ value of 0.82 considered to be a good correlation. The order of log P values was EtNBS-G $<$ EtNBS-A $<$ EtNBS-Ac $<$ EtNBS-N $<$ EtNBS $<$ EtNBS-So = EtNBS-Sp. The order of TPSA values was EtNBS $<$ EtNBS-A $<$ EtNBSAc $<$ EtNBS-So = Et NBS-Sp $<$ EtNBS-N $<$ EtNBS-G.

\section{Spectroscopy}

The absorption spectra of the seven compounds are shown in Figures $1 \mathrm{~A}(\mathrm{MeOH})$ and Figure 1B (water). The spectra in $\mathrm{MeOH}$ had much sharper peaks than they did in water and the overall intensity was also higher in $\mathrm{MeOH}$. This behavior is indicative of the dyes aggregating in water and disaggregating in $\mathrm{MeOH}$. Moreover it is possible that differences in the polarity of the solvents could also affect the spectral features. The order of absorption in $\mathrm{MeOH}$ was EtNBS > EtNBS-N > EtNBS-Sp > EtNBS-So > EtNBS-A > EtNBS-Ac > EtNBS-G. The order of absorption in water was EtNBS $>$ EtNBS-So $>$ EtNBS-So $>$ EtNBS- 
$\mathrm{N}>$ EtNBS-A > EtNBS-G > EtNBS-Ac. The differences between the orders of the compounds in $\mathrm{MeOH}$ and in water are presumably due to differences in solubility between the two solvents. The fluorescence emission spectra after excitation at the absorption maximum of the seven compounds are shown in Figure 2A $(\mathrm{MeOH})$ and Figure 2B (water). The difference between the magnitude of the emission in $\mathrm{MeOH}$ and in water $(\mathrm{MeOH} \gg>$ $\mathrm{H} 2 \mathrm{O}$ ) was even more pronounced than it was for the difference seen in absorption. The order of fluorescence intensity in MeOH was EtNBS $>$ EtNBS-N $>$ EtNBS-Sp $\approx$ EtNBS-G $>$ EtNBS-So > EtNBS-A. EtNBS-Ac had no detectable fluorescence emission at all. In water the order of fluorescence emission was EtNBS > EtNBS-Sp > EtNBS-N > EtNBs-So $>$ EtNBS-G $>$ EtNBS-Ac $\approx$ EtNBS-A.

\section{ROS probe data}

The ROS probe data for the seven compounds are shown in Fig 3A (SOSG) and Fig 3B (HPF). For SOSG the order of effectiveness was as follows: EtNBS $\approx$ EtNBS-So $\approx$ EtNBSSp $>$ EtNBS-G > EtNBS-N > EtNBS-A > EtNBS-Ac (EtNBS-Ac had no more activation than SOSG alone). For HPF the order of effectiveness was EtNBS $>$ EtNBS-Sp $>$ EtNBS-So $>$ EtNBS-G > EtNBS-N > EtNBS-A > EtNBS-Ac (again EtNBS-Ac had hardly more activation than HPF alone).

\section{Antimicrobial PDI}

The aPDI data is shown in Figure 4 (EtNBS), Figure 5 (EtNBS-N), Figure 6 (EtNBS-A), Figure 7 (EtNBS-Ac), Figure 8 (EtNBS-So), Figure 9 (EtNBS-Sp) and Figure 10 (EtNBSG). The parent EtNBS structure was most effective in mediating photokilling of all four microbial cells (Figure 4) with $>6 \operatorname{logs}$ (equivalent to eradication) being obtained with all species. The order of susceptibility was $S$. aureus $>$ E. faecalis $>$ A. baumannii $>$ E. coli. Significant dark toxicity become evident at $50 \mathrm{uM}$ concentration except in the case of $S$. aureus. The 1-substituted nitro-compound (EtNBS-N, Figure 5) only provided good photokilling (5-6 logs) for the two Gram-positive species with E. faecalis being somewhat more susceptible than $S$. aureus. There was only low dark toxicity. The 1-substituted amino compound (EtNBS-A, Figure 6) was only able to mediate PDI of S. aureus and then the killing was less than 3 logs. The acetamido derivative (EtNBS-Ac, Figure 7) did not provide any significant PDI effect, but did have dark toxicity against the Gram-negative species, especially A. baumannii. The 1-substituted N-ethylpropylsulfonamido derivative (EtNBSSo, Figure 8) gave significant killing of both Gram-positive species (4 logs for $S$. aureus and greater than $5 \operatorname{logs}$ for E. faecalis) but not Gram-negatives with low dark toxicity. The 4substituted N-ethylpropylsulfonamido derivative (EtNBS-Sp, Figure 9) gave more PDI of Gram-positive species compared to ETNBS-So (> $5 \operatorname{logs}$ of $S$. aureus and eradication of $E$. faecalis). Again there was no killing of Gram-negatives and no dark toxicity. The quaternized derivative (EtNBS-G, Figure 10) gave substantial killing (> $5 \operatorname{logs}$ ) of all four species, with Gram-negatives being more susceptible (both E. coli and A.baumannii were eradicated. Dark toxicity was low. Therefore the overall order of effectiveness taking into account dark toxicity was EtNBS-G > EtNBS > EtNBS-Sp > EtNBS-N > EtNBS-So > EtNBS-A > EtNBS-Ac.

\section{Bacterial uptake data}

In order to test to what extent the differences we observed in the PDT mediated bacterial killing were due to differences in the affinity of the different dyes for the two kinds of bacterial cells (Gram-positive and Gram-negative), we measured the uptake. Because the fluorescence quantum yield of EtNBS-Ac was close to zero, we were not able to obtain meaningful data for the bacterial binding of this compound. The binding for the remaining six compounds is shown in Figures 11A-D. There were differences in the broad overall 
compound uptake between different bacterial species. A. baumannii (Figure 11D) was the highest, followed by S. aureus (Figure 11A), then E. faecalis (Figure 11B) and E. coli (Figure 11C) was the lowest. Although we do not have formal proof of this, we have evidence that suggests that Acinetobacter baumannii does not have the same permeability barrier shared by many other Gram-negative bacteria such as E. coli and P. aeruginosa. This explains why several investigators have reported that $A$. baumannii is particularly susceptible to PDT. The highest bacterial uptakes amongst the six compounds were seen with EtNBS, EtNBS-N and EtNBS-G, which were also the three compounds which showed the highest degree of photodynamic bacterial killing. Conversely the three compounds with the lowest uptake were also the least active in photodynamic killing. It should be noted that the uptake of EtNBS-Sp (more photodynamically active) was in every case higher than the uptake of EtNBS-So (less photodynamically active). Although the uptake measurements did parallel the order of photodynamic activity for E. faecalis, but not so much for other species, we concluded that differences in uptake could not fully explain the large differences in activity. The differences in activity can be explained by a complex combination of differences in uptake and differences in photochemical activity as shown by absorption and fluorescence spectroscopy and by ROS probe studies.

\section{Discussion}

\section{Comparison of EtNBS and 1-substituted derivatives}

The somewhat surprising reduction in absorption, fluorescence, ROS generating ability and the PDT activity for the three 1-substituted derivatives of EtNBS compared to the parent EtNBS compound led to the hypothesis that the substituent at the 1 position interfered with the $\mathrm{N}$-atom at the 12-position of the benzophenothiazinium ring system and distorted the planar conjugated structure of the tricyclic ring system, thus impairing the photoactivity. This hypothesis was bolstered by the observation that EtNBS-Ac with the bulkiest 1substituent, showed the largest drop in absorption of the four compounds compared, had no detectable fluorescence and was completely unable to generate either $1 \mathrm{O} 2$ or $\mathrm{HO} \bullet$ and could not even kill any Gram-positive bacteria after illumination. However EtNBS-So has an even bulkier group in the 1-position and showed considerably more activity than EtNBS-Ac, so this explanation does not completely account for the observation. There was also an interesting finding that an electron withdrawing substituent in the 1-position was more effective than an electron donating substituent. The reasons for this difference can only be speculated on but include the idea that electron transfer reactions from or to the excited state of the benzophenothiazinium dye (Type I mechanism) could be influenced by the presence of electron withdrawing substituents. There were also differences in bacterial uptake observed by changing the 1-substituent. The unsubstituted EtNBS had high cell uptake but so also did the electron-withdrawing EtNBS-N. The electron donating ETNBS-A had lower uptake while the uptake of EtNBS-Ac could not be measured. The possibility that it was overall lipophilicity rather than steric or electronic factors that primarily influenced the PDU efficacy was tested by calculating $\log$ P and TPSA values (Table 1). The PDI efficacy correlated well with descending $\log$ P value EtNBS $>$ EtNBS-N $>$ EtNBS-A $>$ EtNBS-Ac, but not with TPSA values EtNBS-N $>$ EtNBS-A $>$ EtNBS-A $>$ EtNBS.

\section{Comparison of 1 and 4-substituted sulfonamide derivatives}

To test the hypothesis outlined above (distortion of the ring planarity by a 1-substituent) we prepared two isomeric derivatives with the same bulky N-ethylpropylsulfonamido group substituted either at the 1-position or at the 4-position of the benzene ring. The absorption of the 4-isomer (EtNBS-Sp) was somewhat higher than that of the 1-isomer (EtNBS-So) both in water and methanol. Furthermore the fluorescence of EtNBS-Sp was 2.5 times higher than that of EtNBS-So in methanol (Fig 2A) and 14 times higher in water (Fig 2B). 
However the ROS generation showed that SOSG was activated to a similar degree by EtNBS-Sp compared to EtNBS-So (Fig 3A), while HPF was activated about 25\% more (Fig 3B). The photokilling of $S$.aureus was also higher for the 4-isomer than for the 1-isomer (although not by a large amount). Taken together these data confirm the hypothesis that reduction in the photoactivity of the benzophenothiazinium ring is partly due to 1substituents distorting the planar ring structure. However the bacterial uptake of the less active EtNBS-So was consistently lower than the uptake of the more active EtNBS-Sp for all species suggesting that bacterial binding is also important in determining the effectiveness of PDI. It may be the case that the more planar structure of the unmodified EtNBS favors bacterial binding, while the distorted ring structures of the derivatives do not bind to the bacterial cell walls so effectively.

\section{Comparison of EtNBS and arginine derivative}

We decided to synthesize an arginine derivative of EtNBS based on the hypothesis that an extra basic guanidine imino-group would impart enough additional cationic charge to EtNBS to increase its activity against Gram-negative bacteria, where pronounced cationic charge is known to be the most advantageous molecular feature [8]. The product EtNBS-G had lower activity than the parent EtNBS against the Gram-positive $S$. aureus as expected since it has been reported that a large number of cationic groups on an antimicrobial photosensitizer are not beneficial for enhancing performance against Gram-positive bacteria [26, 27]. However the PDI activity was enhanced against the Gram-negative species, and especially the ratio between the light-mediated toxicity (PDI) and the dark toxicity was improved in the case of EtNBS-G. This observation is presumably because the dark toxicity of EtNBS is mediated by lipophilic disruption of bacterial membranes due to uptake of the hydrophobic dye as has been shown for phenothiazinium analogues such as dimethyl methylene blue $[28,29]$. By contrast, the high activity of EtNBS-G is due to the guanidinium charge mediating the displacement of divalent cations $\left(\mathrm{Ca}^{2+}\right.$ and $\left.\mathrm{Mg}^{2+}\right)$ in the LPS structure of the cell wall as reported for cationic phthalocyanines [30], and this type of cell disruption does not cause marked dark toxicity, but does allow efficient PDI.

\section{Conclusion}

In retrospect, we might not have chosen to synthesize 1-substituted EtNBS derivatives had we known the results of the study a priori. But although we did not succeed to prepare more potent analogues of EtNBS as antimicrobial photosensitizers as we originally hoped, we did discover some interesting new information about the effects that molecular geometry has on the absorption spectra, fluorescence emission, photoproduction of ROS and antimicrobial PDI capacity of these benzophenothiazinium dye derivatives. The large differences in PDI activity amongst the seven dye molecular structures were found to be due to a complex interrelationship between differences in photochemical generation of the $\operatorname{ROS~}^{1} \mathrm{O}_{2}$ and $\mathrm{HO}$ ' and differences in binding to the Gram-positive and Gram-negative bacterial cell walls. The addition of a guanidine residue to an existing amino group may be a general way of increasing the overall cationic charge on antimicrobial photosensitizer and increasing its activity against Gram-negative bacteria. The data also suggest that compounds bearing two (or even three cationic charges) may be the best candidates for maximizing the antimicrobial PDI activity of this class of compounds.

\section{Supplementary Material}

Refer to Web version on PubMed Central for supplementary material. 


\section{Acknowledgments}

This work was supported by US NIH grant R01AI050875 to MRH and US NIH Director's New Innovator Award, grant number DP2OD007096 to CLE. Information on the New Innovator Award Program is at http:// nihroadmap.nih.gov/newinnovator/. The funding sources had no involvement in the study design; in the collection, analysis and interpretation of data; in the writing of the report; or in the decision to submit the article for publication.

\section{Abbreviations}

CFU colony forming units

DMA N,N-dimethylacetamide

EtNBA 5-ethylamino-9-diethylaminobenzo[a]phenoxazinium chloride

EtNBS 5-ethylamino-9-diethylaminobenzo[a]phenthiazinium chloride

EtNBSe 5-ethylamino-9-diethylaminobenzo[a]phenoselenazinium chloride

EtNBS-N N-(9-(diethylamino)-1-nitro-5H-benzo[a]phenothiazin-5ylidene)ethanaminium chloride

EtNBS-A N-(1-amino-9-(diethylamino)-5H-benzo[a]phenothiazin-5ylidene)ethanaminium chloride

EtNBS-Ac N-(1-acetamido-9-(diethylamino)-5H-benzo[a]phenothiazin-5-ylidene)ethanaminium chloride

EtNBS-So $\quad \mathrm{N}$-(9-(diethylamino)-1-(N-ethylpropylsulfonamido)-5Hbenzo[a]phenothiazin-5-ylidene)ethanaminium chloride

EtNBS-Sp N-(9-(diethylamino)-4-(N-ethylpropylsulfonamido)-5Hbenzo[a]phenothiazin-5-ylidene)ethanaminium chloride

EtNBS-G 2-((amino(iminio)methyl)amino)-N-(9-(diethylamino)-5Hbenzo[a]phenothiazin-5-ylidene)ethanaminium chloride

HPF 3-(4-hydroxyphenyl)fluorescein

PBS phosphate buffered saline

PDT photodynamic therapy

PS photosensitizer

ROS reactive oxygen species

SAR structure activity relationship

SOSG singlet oxygen sensor green

\section{References}

1. van Duijn PJ, Dautzenberg MJ, Oostdijk EA. Recent trends in antibiotic resistance in European ICUs. Curr Opin Crit Care. 2011; 17:658-665. [PubMed: 21986462]

2. Kharkwal GB, Sharma SK, Huang YY, Dai T, Hamblin MR. Photodynamic therapy for infections: Clinical applications. Lasers Surg Med. 2011; 43:755-767. [PubMed: 22057503]

3. Agostinis P, Berg K, Cengel KA, Foster TH, Girotti AW, Gollnick SO, Hahn SM, Hamblin MR, Juzeniene A, Kessel D, Korbelik M, Moan J, Mroz P, Nowis D, Piette J, Wilson BC, Golab J. Photodynamic therapy of cancer: An update. CA Cancer J Clin. 2011; 61:250-281. [PubMed: 21617154] 
4. Chan WM, Lim TH, Pece A, Silva R, Yoshimura N. Verteporfin PDT for non-standard indications-a review of current literature. Graefes Arch Clin Exp Ophthalmol. 2010; 248:613-626. [PubMed: 20162298]

5. Harris F, Chatfield LK, Phoenix DA. Phenothiazinium based photosensitisers--photodynamic agents with a multiplicity of cellular targets and clinical applications. Curr Drug Targets. 2005; 6:615-627. [PubMed: 16026282]

6. Merchat M, Bertolini G, Giacomini P, Villanueva A, Jori G. Meso-substituted cationic porphyrins as efficient photosensitizers of gram-positive and gram-negative bacteria. J Photochem Photobiol B. 1996; 32:153-157. [PubMed: 8622178]

7. Hamblin MR, Hasan T. Photodynamic therapy: a new antimicrobial approach to infectious disease? Photochem.Photobiol.Sci. 2004; 3:436-450. [PubMed: 15122361]

8. Sharma SK, Dai T, Kharkwal GB, Huang YY, Huang L, Bil De Arce VJ, Tegos GP, Hamblin MR. Drug discovery of antimicrobial photosensitizers using animal models. Curr Pharm Des. 2011; 17:1303-1319. [PubMed: 21504410]

9. Sgolastra F, Petrucci A, Severino M, Graziani F, Gatto R, Monaco A. Adjunctive photodynamic therapy to non-surgical treatment of chronic periodontitis: a systematic review and meta-analysis. $\mathrm{J}$ Clin Periodontol. 2013; 40:514-526. [PubMed: 23557433]

10. Konopka K, Goslinski T. Photodynamic therapy in dentistry. J Dent Res. 2007; 86:694-707. [PubMed: 17652195]

11. Cincotta L, Foley JW, Cincotta AH. Phototoxicity, redox behavior, and pharmacokinetics of benzophenoxazine analogues in EMT-6 murine sarcoma cells. Cancer Res. 1993; 53:2571-2580. [PubMed: 8495421]

12. Klein OJ, Bhayana B, Park YJ, Evans CL. In vitro optimization of EtNBS-PDT against hypoxic tumor environments with a tiered, high-content, 3D model optical screening platform. Molecular pharmaceutics. 2012; 9:3171-3182. [PubMed: 22946843]

13. Evans CL, Abu-Yousif AO, Park YJ, Klein OJ, Celli JP, Rizvi I, Zheng X, Hasan T. Killing hypoxic cell populations in a 3D tumor model with EtNBS-PDT. PloS one. 2011; 6:e23434. [PubMed: 21876751]

14. Cincotta L, Foley JW, MacEachern T, Lampros E, Cincotta AH. Novel photodynamic effects of a benzophenothiazine on two different murine sarcomas. Cancer Res. 1994; 54:1249-1258. [PubMed: 8118813]

15. Frimberger AE, Moore AS, Cincotta L, Cotter SM, Foley JW. Photodynamic therapy of naturally occurring tumors in animals using a novel benzophenothiazine photosensitizer. Clin Cancer Res. 1998; 4:2207-2218. [PubMed: 9748141]

16. Hendrzak-Henion JA, Knisely TL, Cincotta L, Cincotta E, Cincotta AH. Role of the immune system in mediating the antitumor effect of benzophenothiazine photodynamic therapy. Photochem Photobiol. 1999; 69:575-581. [PubMed: 10333764]

17. Foley JW, Song X, Demidova TN, Jalil F, Hamblin MR. Synthesis and properties of benzo[a]phenoxazinium chalcogen analogues as novel broad-spectrum antimicrobial photosensitizers. J Med Chem. 2006; 49:5291-5299. [PubMed: 16913718]

18. O'Riordan K, Akilov OE, Chang SK, Foley JW, Hasan T. Real-time fluorescence monitoring of phenothiazinium photosensitizers and their anti-mycobacterial photodynamic activity against Mycobacterium bovis BCG in in vitro and in vivo models of localized infection. Photochemical \& photobiological sciences : Official journal of the European Photochemistry Association and the European Society for Photobiology. 2007; 6:1117-1123. [PubMed: 17914486]

19. Verma S, Sallum UW, Athar H, Rosenblum L, Foley JW, Hasan T. Antimicrobial photodynamic efficacy of side-chain functionalized benzo[a]phenothiazinium dyes. Photochem Photobiol. 2009; 85:111-118. [PubMed: 18657053]

20. Akilov OE, Kosaka S, O'Riordan K, Song X, Sherwood M, Flotte TJ, Foley JW, Hasan T. The role of photosensitizer molecular charge and structure on the efficacy of photodynamic therapy against Leishmania parasites. Chem Biol. 2006; 13:839-847. [PubMed: 16931333]

21. Klein OJ, Bhayana B, Park YJ, Evans CL. In Vitro Optimization of EtNBS-PDT against Hypoxic Tumor Environments with a Tiered, High-Content, 3D Model Optical Screening Platform. Mol Pharm. 2012; 9:3171-3182. [PubMed: 22946843] 
22. Foley, JW.; Cincotta, L. Photo-inactivation of Cancer Cells. 1990. U.S. Patent, 4,962,197

23. Feichtinger K, Zapf C, Sings HL, Goodman M. Diprotected triflylguanidines: a new class of guanidinylation reagents. The Journal of Organic Chemistry. 1998; 63:3804-3805.

24. Fernandes J, Gattass CR. Topological polar surface area defines substrate transport by multidrug resistance associated protein 1 (MRP1/ABCC1). J Med Chem. 2009; 52:1214-1218. [PubMed: 19193010]

25. Jett BD, Hatter KL, Huycke MM, Gilmore MS. Simplified agar plate method for quantifying viable bacteria. Biotechniques. 1997; 23:648-650. [PubMed: 9343684]

26. Huang L, Huang YY, Mroz P, Tegos GP, Zhiyentayev T, Sharma SK, Lu Z, Balasubramanian T, Krayer M, Ruzie C, Yang E, Kee HL, Kirmaier C, Diers JR, Bocian DF, Holten D, Lindsey JS, Hamblin MR. Stable synthetic cationic bacteriochlorins as selective antimicrobial photosensitizers. Antimicrob Agents Chemother. 2010; 54:3834-3841. [PubMed: 20625146]

27. Huang L, Terakawa M, Zhiyentayev T, Huang YY, Sawayama Y, Jahnke A, Tegos GP, Wharton T, Hamblin MR. Innovative cationic fullerenes as broad-spectrum light-activated antimicrobials. Nanomedicine. 2010; 6:442-452. [PubMed: 19914400]

28. Wainwright M, Phoenix DA, Marland J, Wareing DR, Bolton FJ. A study of photobactericidal activity in the phenothiazinium series. FEMS Immunol Med Microbiol. 1997; 19:75-80. [PubMed: 9322071]

29. Wainwright M, Phoenix DA, Rice L, Burrow SM, Waring J. Increased cytotoxicity and phototoxicity in the methylene blue series via chromophore methylation. Journal of photochemistry and photobiology. B, Biology. 1997; 40:233-239.

30. Minnock A, Vernon DI, Schofield J, Griffiths J, Parish JH, Brown SB. Mechanism of uptake of a cationic water-soluble pyridinium zinc phthalocyanine across the outer membrane of Escherichia coli. Antimicrob Agents Chemother. 2000; 44:522-527. [PubMed: 10681312] 


\section{Highlights}

Seven derivatives of Nile blue EtNBS have been synthesized and characterized

Absorption, fluorescence, light-mediated reactive oxygen species generation and bacterial killing

1-substituents were less active than parent with electron withdrawing better than electron donating

4-substituents were better than 1-substituents, and a guanidinium killed Gram-negatives

Effectiveness as antimicrobial photosensitzers is a mixture of bacterial uptake and photochemistry 

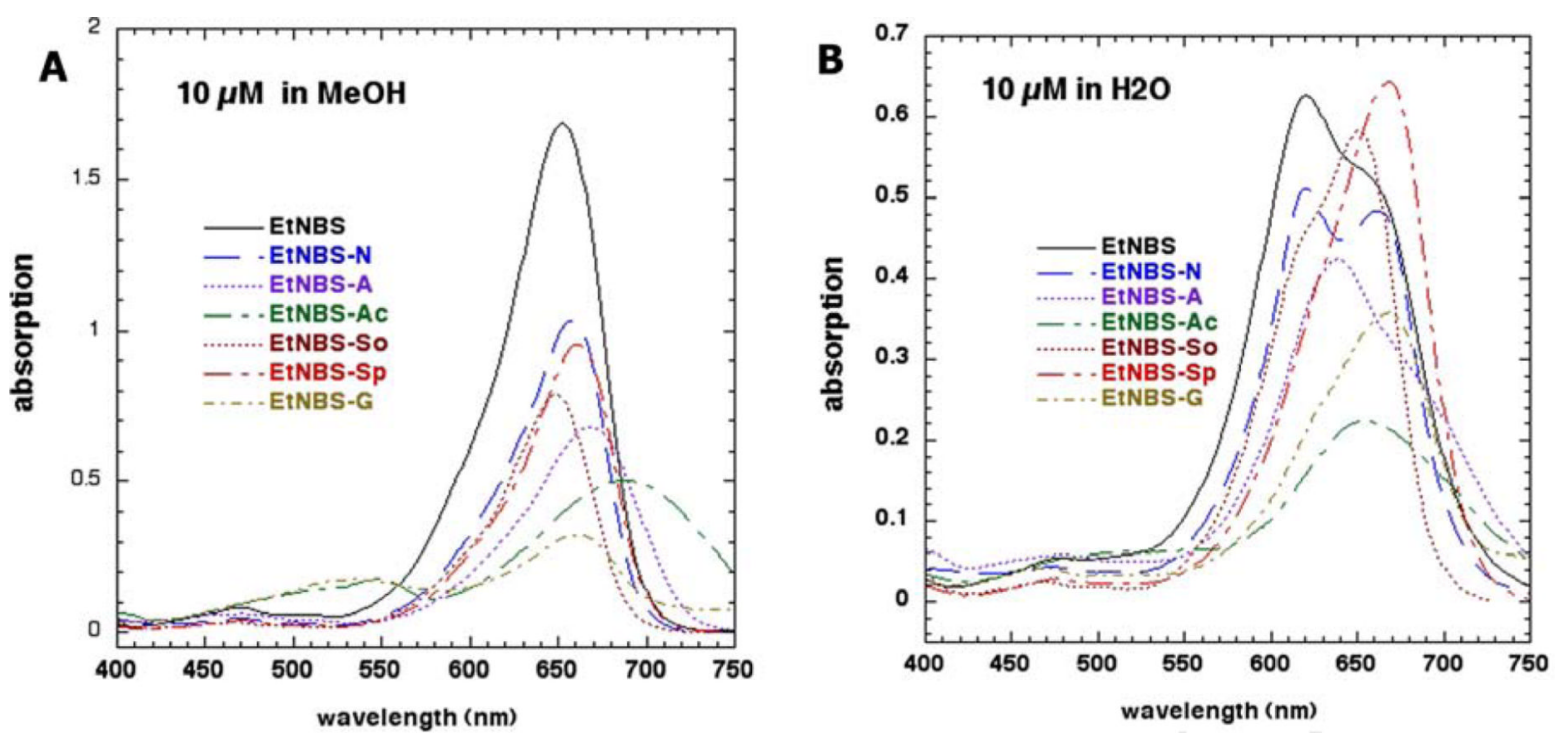

Figure 1.

Absorption spectra of the seven EtNBS analogues (A) $10 \mu \mathrm{M}$ in methanol and (B) $10 \mu \mathrm{M}$ in double distilled water. 

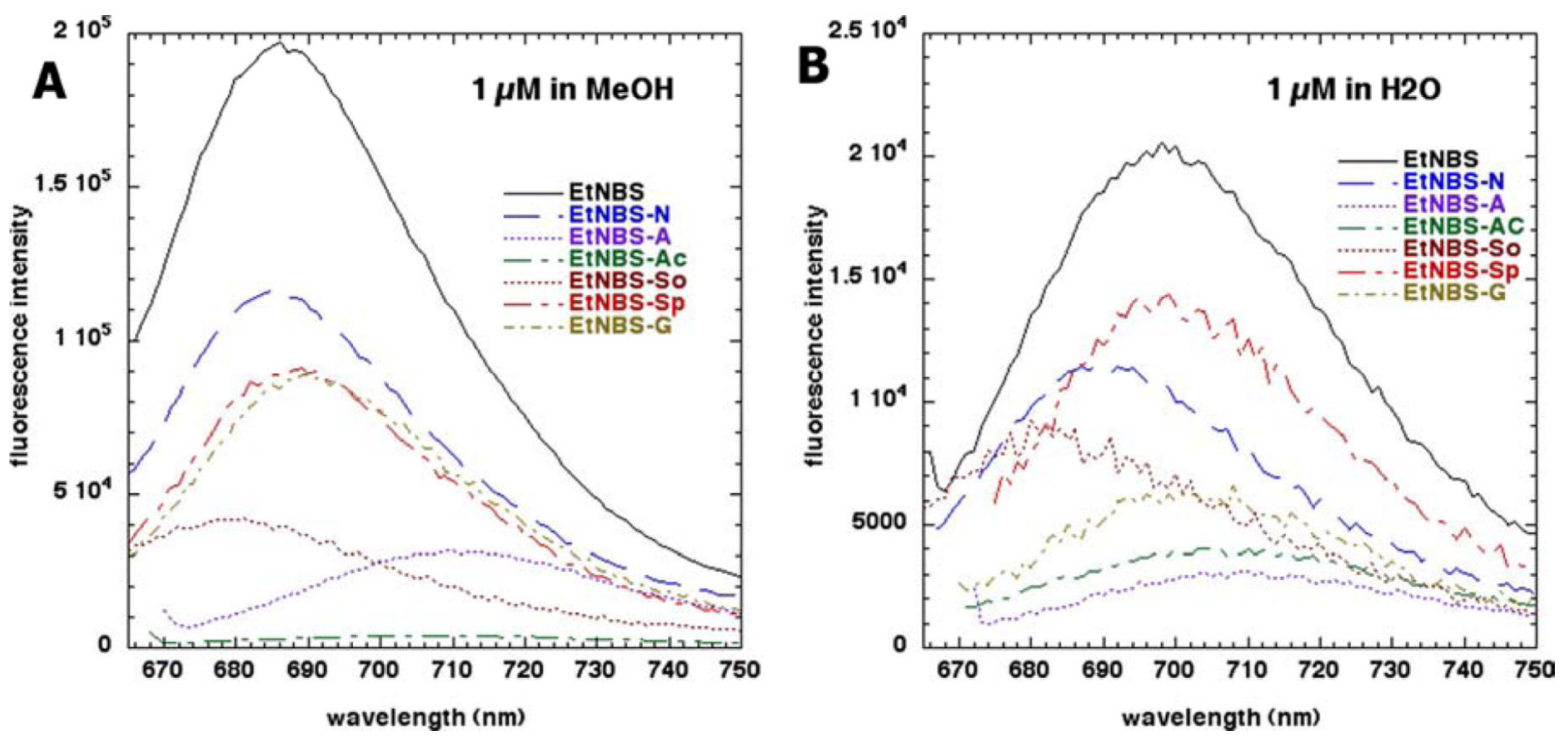

Figure 2.

Fluorescence emission spectra after excitation at the absorption maximum for each compound of the seven EtNBS analogues (A) $1 \mu \mathrm{M}$ in methanol and (B) $1 \mu \mathrm{M}$ in double distilled water. 

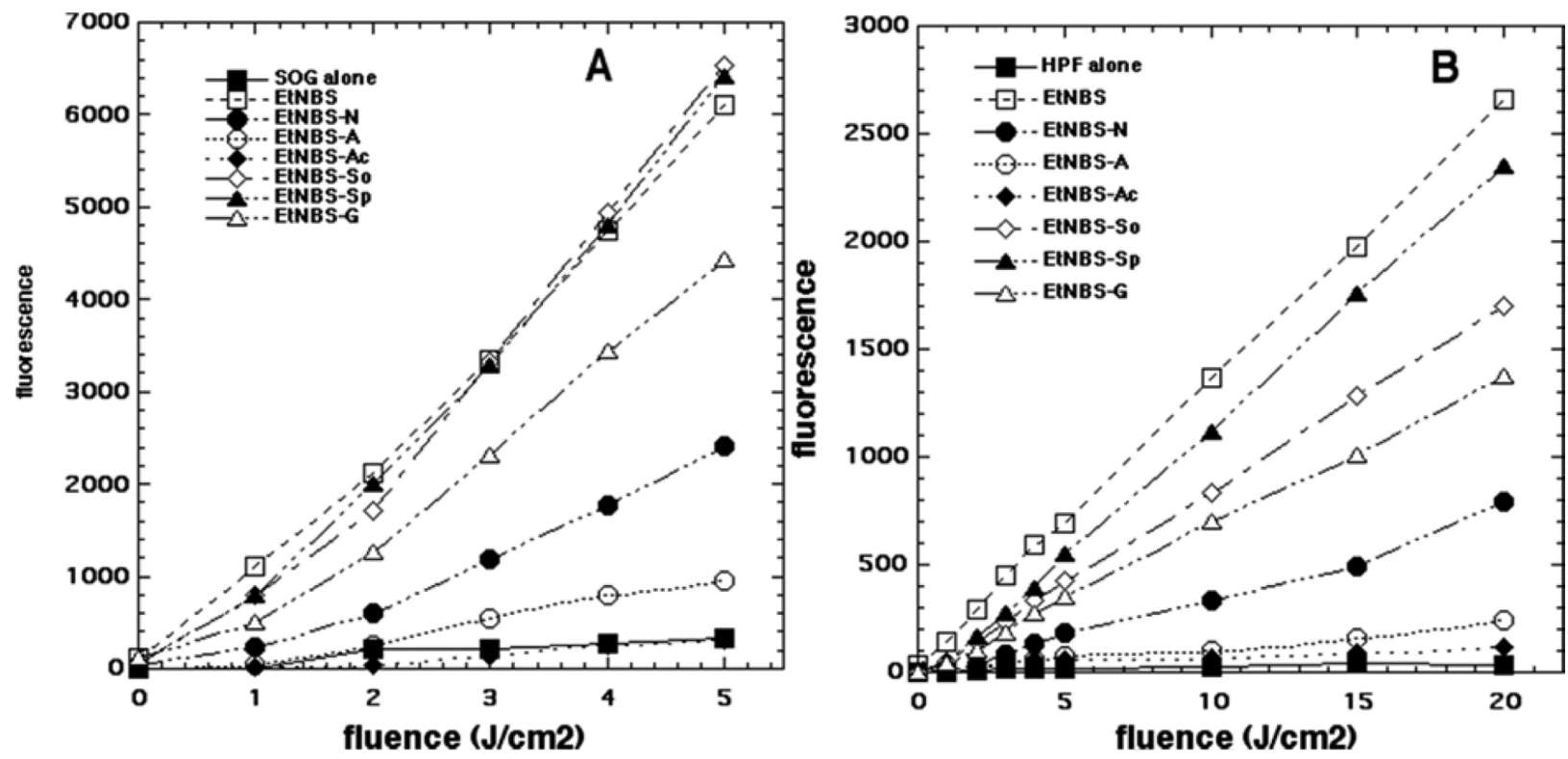

Figure 3.

Activation of fluorescent ROS probes $(5 \mu \mathrm{M})$ in PBS with the seven EtNBS analogues (5 $\mu \mathrm{M})$ exposed to increasing fluences of 635 -nm light. (A) Singlet oxygen sensor green (SOSG); (b) Hydroxyphenyl-fluorescein (HPF). 

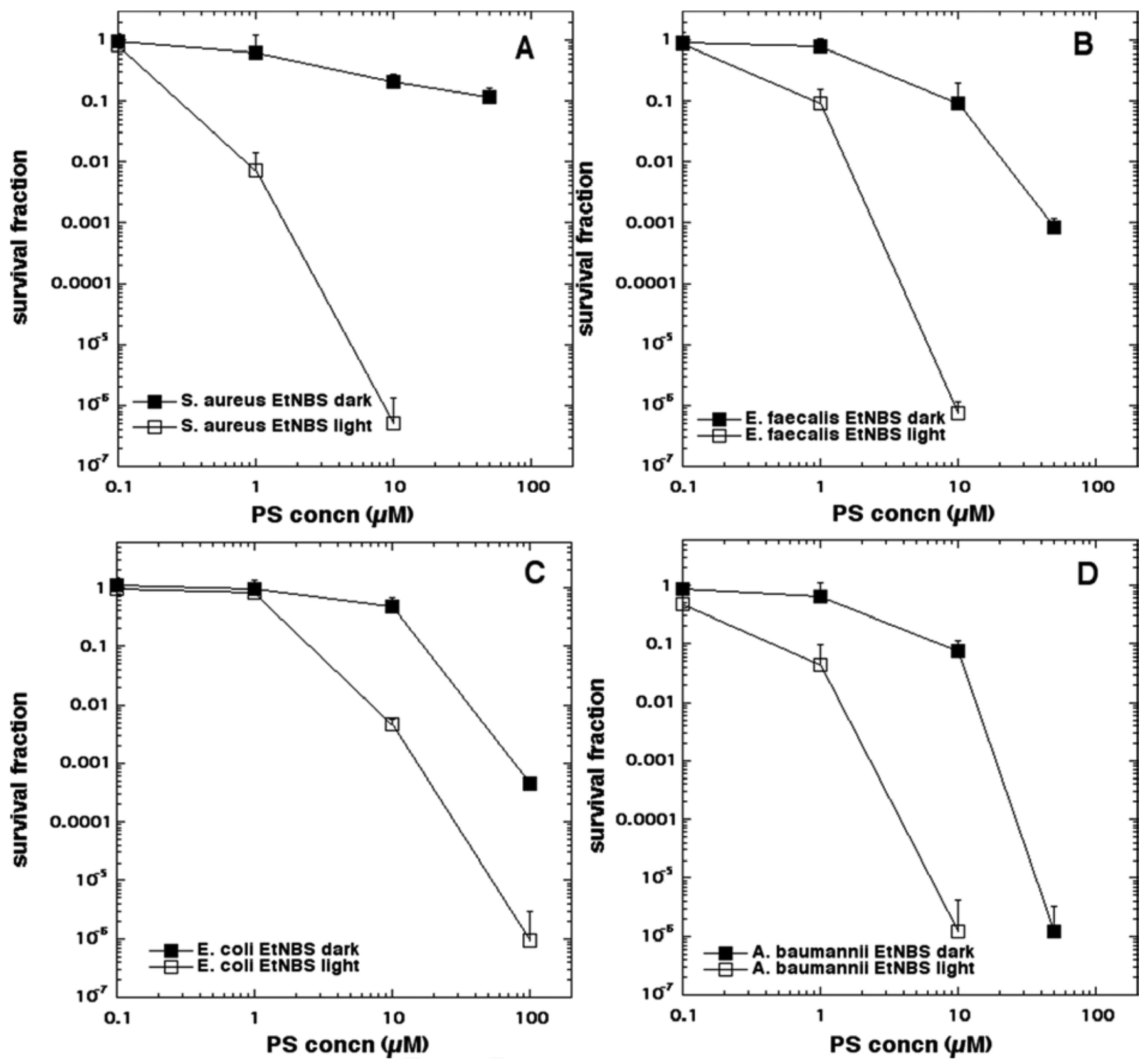

Figure 4.

Antimicrobial PDI of the four bacteria incubated with increasing concentrations of EtNBS and exposed after $10 \mathrm{~min}$ to $10 \mathrm{~J} / \mathrm{cm}^{2}$ of 635 -nm light. (A) S. aureus; (B) E. faecalis; (C) E. coli; (D) A. baumannii. 

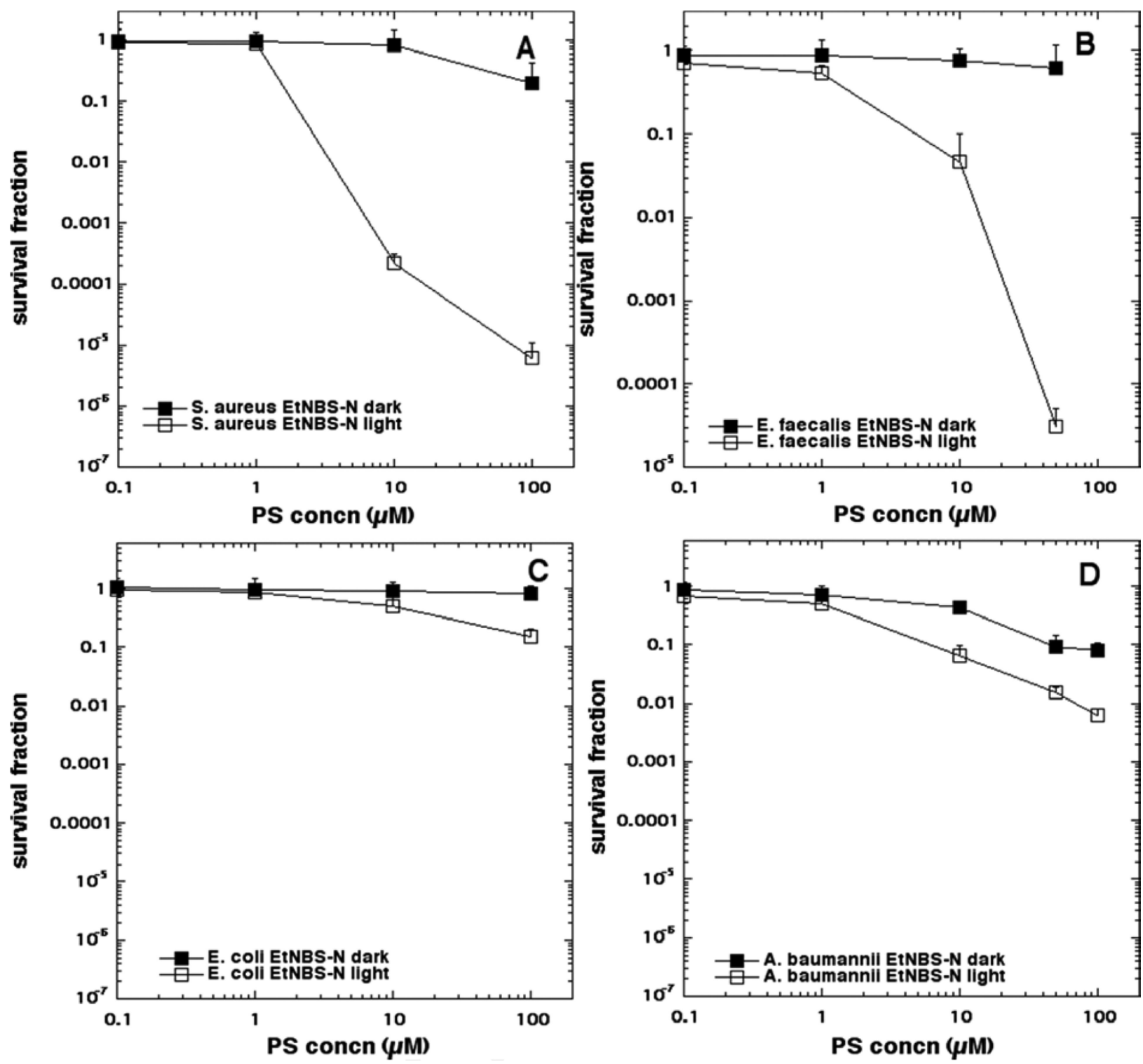

Figure 5.

Antimicrobial PDI of the four bacteria incubated with increasing concentrations of EtNBS-N and exposed after $10 \mathrm{~min}$ to $10 \mathrm{~J} / \mathrm{cm}^{2}$ of 635-nm light. (A) S. aureus; (B) E. faecalis; (C) $E$. coli; (D) A. baumannii. 

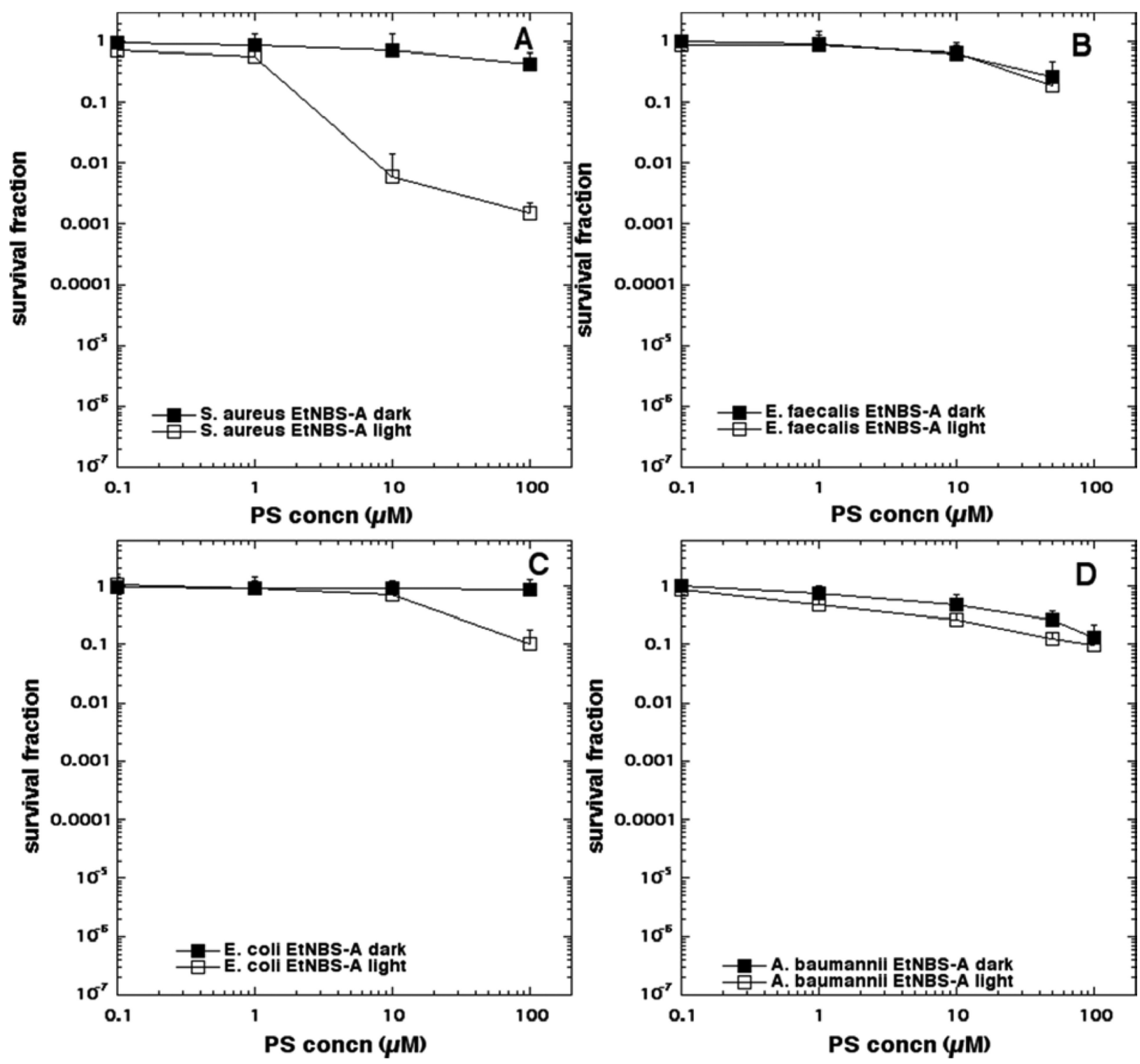

Figure 6.

Antimicrobial PDI of the four bacteria incubated with increasing concentrations of EtNBS-A and exposed after $10 \mathrm{~min}$ to $10 \mathrm{~J} / \mathrm{cm}^{2}$ of 635 -nm light. (A) S. aureus; (B) E. faecalis; (C) E. coli; (D) A. baumannii. 

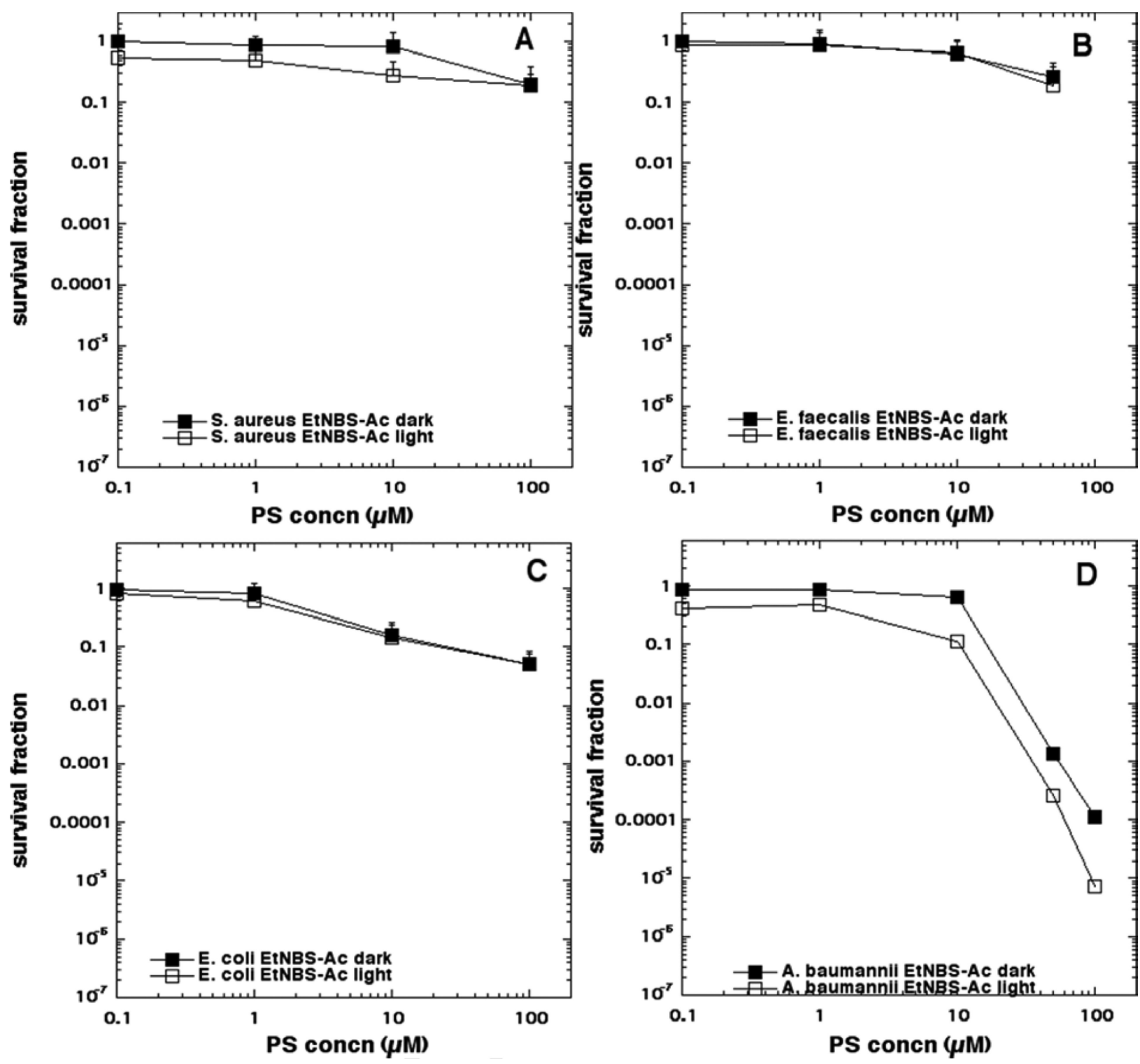

Figure 7.

Antimicrobial PDI of the four bacteria incubated with increasing concentrations of EtNBSAc and exposed after $10 \mathrm{~min}$ to $10 \mathrm{~J} / \mathrm{cm}^{2}$ of 635 -nm light. (A) S. aureus; (B) E. faecalis; (C) E. coli; (D) A. baumannii. 

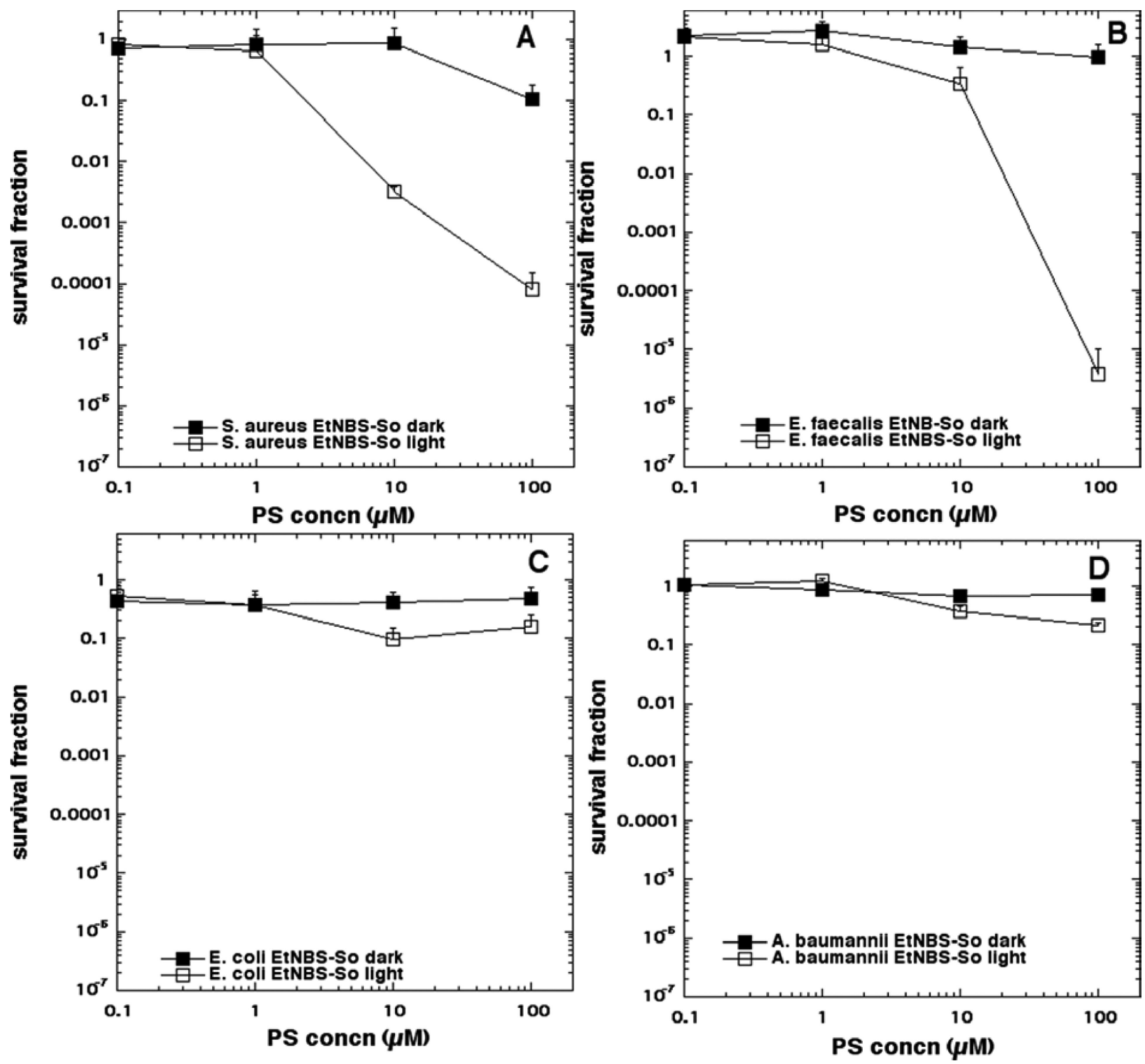

Figure 8.

Antimicrobial PDI of the four bacteria incubated with increasing concentrations of EtNBSSo and exposed after $10 \mathrm{~min}$ to $10 \mathrm{~J} / \mathrm{cm}^{2}$ of $635-\mathrm{nm}$ light. (A) S. aureus; (B) E. faecalis; (C) E. coli; (D) A. baumannii. 

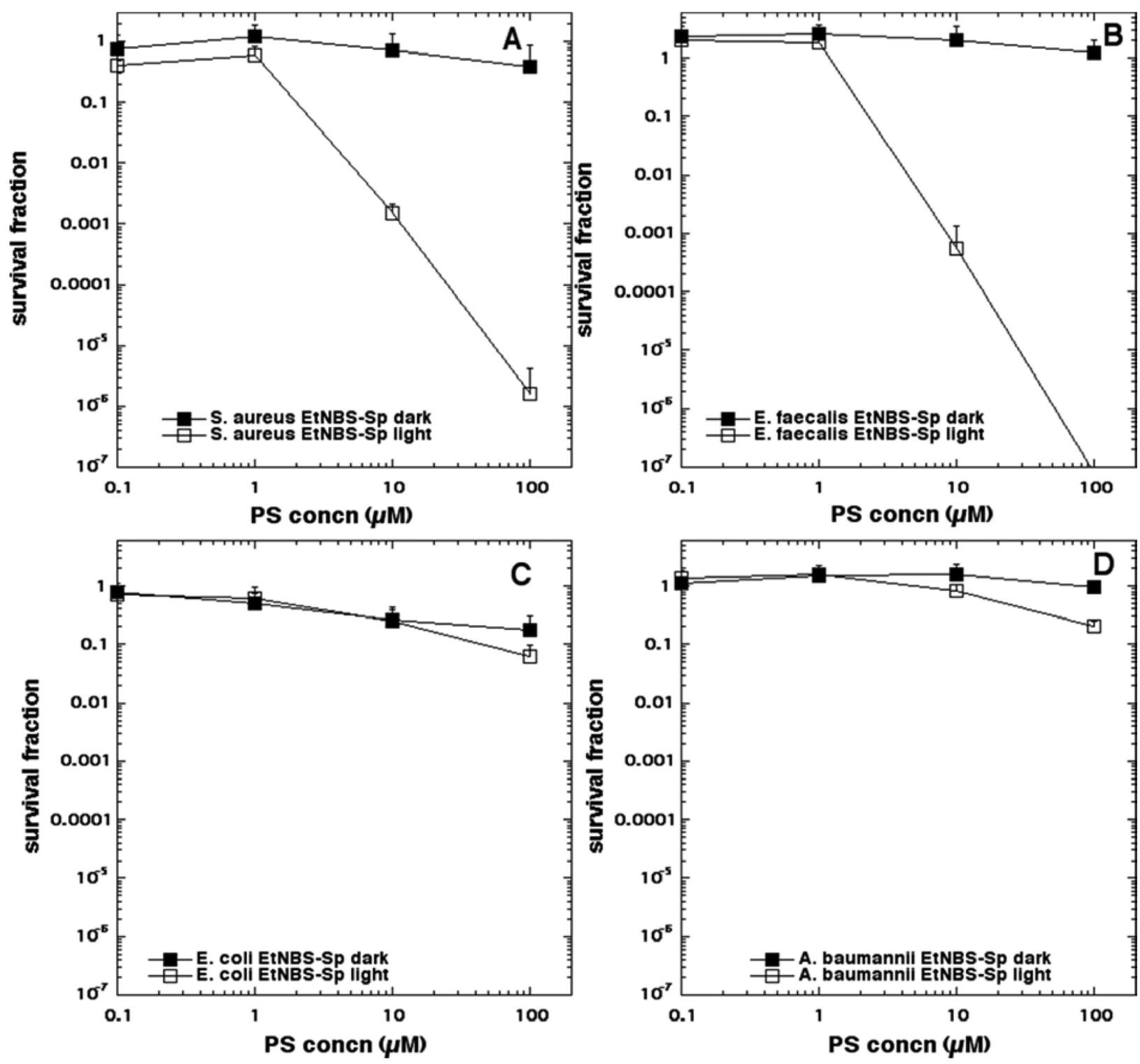

Figure 9.

Antimicrobial PDI of the four bacteria incubated with increasing concentrations of EtNBSSp and exposed after $10 \mathrm{~min}$ to $10 \mathrm{~J} / \mathrm{cm}^{2}$ of $635-\mathrm{nm}$ light. (A) S. aureus; (B) E. faecalis; (C) E. coli; (D) A. baumannii. 

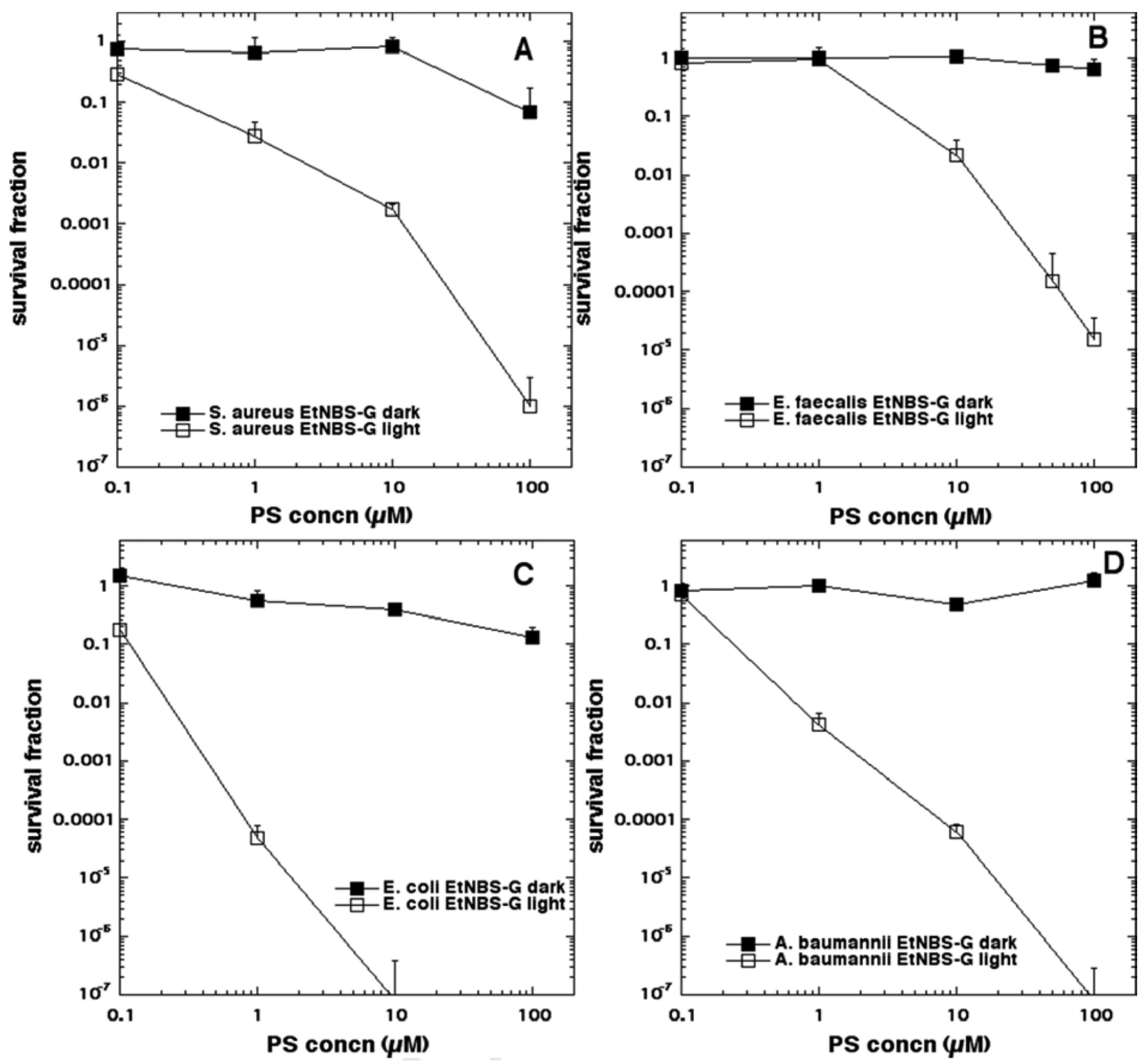

Figure 10.

Antimicrobial PDI of the four bacteria incubated with increasing concentrations of EtNBS-G and exposed after $10 \mathrm{~min}$ to $10 \mathrm{~J} / \mathrm{cm}^{2}$ of 635 -nm light. (A) S. aureus; (B) E. faecalis; (C) E. coli; (D) A. baumannii. 

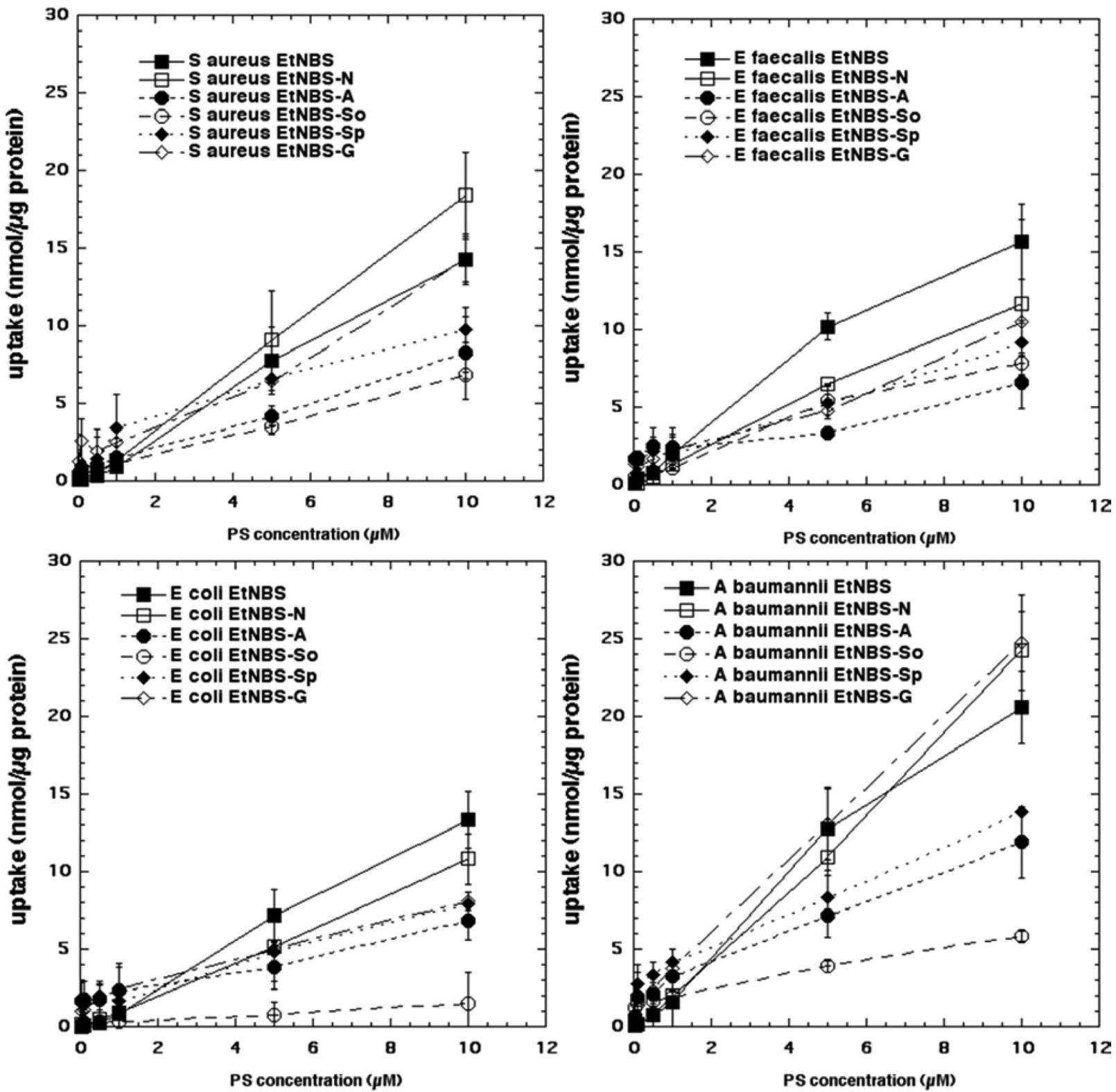

Figure 11.

Uptake (calculated via fluorescence calibration curves and protein determination) of the six EtNBS analogues (EtNBS-Ac had too low fluorescence to be measured) by the four bacteria after 10 min incubation. (A) S. aureus; (B) E. faecalis; (C) E. coli; (D) A. baumannii. 
Table 1

Structures of the seven benzophenothiazinium dyes, $\operatorname{LogP}$ and TPSA values.

\begin{tabular}{|c|c|c|c|c|}
\hline Compound & Structure & Calc $\log \mathrm{P}^{a}$ & Meas $\log \mathrm{P}^{b}$ & TPSA $^{c}$ \\
\hline EtNBS & 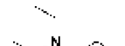 & 1.74 & $2.87 \pm 0.19$ & 29.57 \\
\hline EtNBS-N & & 1.503 & $2.03 \pm 0.27$ & 81.38 \\
\hline EtNBS-A & & 0.76 & $1.77 \pm 0.42$ & 55.59 \\
\hline EtNBS-Ac & & 0.98 & $1.36 \pm 0.2$ & 58.67 \\
\hline EtNBS-So & & 2.35 & $2.19 \pm 0.16$ & 66.95 \\
\hline EtNBS-Sp & & 2.35 & $2.45 \pm 012$ & 66.95 \\
\hline EtNBS-G & & 0.25 & $0.49 \pm 0.26$ & 93.21 \\
\hline
\end{tabular}

${ }^{a} \log (10)$ of octanol:water partition coefficient calculated by ChemBioDraw.

${ }^{b}$ Measured Log P values determined experimentally

${ }^{c}$ Topological polar surface area calculated by ChemBioDraw. 